\title{
Research Article \\ Energy Characterization and Gasification of Biomass Derived by Hazelnut Cultivation: Analysis of Produced Syngas by Gas Chromatography
}

\author{
D. Monarca, ${ }^{1}$ A. Colantoni, ${ }^{1}$ M. Cecchini, ${ }^{1}$ L. Longo, ${ }^{1}$ \\ L. Vecchione, ${ }^{1}$ M. Carlini, ${ }^{1}$ and A. Manzo ${ }^{2}$ \\ ${ }^{1}$ Department of Agriculture, Forest, Nature and Energy (DAFNE), University of Tuscia, \\ Via S. Camillo de Lellis snc, 01100 Viterbo, Italy \\ ${ }^{2}$ Ministry of Agriculture, Food and Forestry, Via XX Settembre 20, 00100 Rome, Italy \\ Correspondence should be addressed to A. Colantoni, colantoni@unitus.it
}

Received 22 August 2012; Accepted 21 September 2012

Academic Editor: Nataliya Krasnogorskaya

Copyright (C) 2012 D. Monarca et al. This is an open access article distributed under the Creative Commons Attribution License, which permits unrestricted use, distribution, and reproduction in any medium, provided the original work is properly cited.

\begin{abstract}
Modern agriculture is an extremely energy intensive process. However, high agricultural productivities and the growth of green revolution has been possible only by large amount of energy inputs, especially those coming from fossil fuels. These energy resources have not been able to provide an economically viable solution for agricultural applications. Biomass energybased systems had been extensively used for transportation and on farm systems during World War II: the most common and reliable solution was wood or biomass gasification. The latter means incomplete combustion of biomass resulting in production of combustible gases which mostly consist of carbon monoxide $(\mathrm{CO})$, hydrogen $\left(\mathrm{H}_{2}\right)$ and traces of methane $\left(\mathrm{CH}_{4}\right)$. This mixture is called syngas, which can be successfully used to run internal combustion engines (both compression and spark ignition) or as substitute for furnace oil in direct heat applications. The aim of the present paper is to help the experimentation of innovative plants for electric power production using agro-forest biomass derived by hazelnut cultivations. An additional purpose is to point out a connection among the chemical and physical properties of the outgoing syngas by biomass characterization and gas-chromatography analysis.
\end{abstract}

\section{Introduction}

The global environment conditions are badly influenced by the exploitation and the extreme utilization of typical energetic sources, which is mainly due to industrialized countries and exponential population growth. Industrialization leads to atmospheric emissions of pollutants and greenhouse gases, whose carbon dioxide $\left(\mathrm{CO}_{2}\right)$ is considered as the most 
important. Even if it is not toxic, $\mathrm{CO}_{2}$ is extremely dangerous because it may cause global overheating and climate change. This work is based on the idea of energetically independent agroforest farms, able to generate electric power using renewable sources as agroforest biomass from agricultural discards [1,2].

If we consider this idea applied on a large scale, we could create an agroenergetic ecodistrict. This concept would have potential benefits for environment, such as reduction of $\mathrm{CO}_{2}$ emissions, and also for farmers, because they could sell the electric power and receive green certificates. The aim of the present work is to help the experimentation of innovative plants for electric power production using agroforest biomass. An additional purpose is to point out a connection among the chemical and physical properties of the outgoing syngas by biomass characterization and gas chromatography analysis.

\section{Material and Methods}

The tests were carried out using hazelnut (Corylus avellana L.) shells by farms located in the area of Lake of Vico, in the province of Viterbo (Latium region). The gasification reactor is a small plant: its capacity reaches $30 \mathrm{kWe}$ and $60 \mathrm{kWt}$ which are the appropriate values for small local farms. The used biomass and the outgoing syngas were analyzed in laboratory in order to assess the potential energy of the residual biomass in relation to that of the produced syngas. This is to evaluate the effectiveness of the gasification process. The purpose of this study is to obtain a gas which can be successfully used in internal combustion engines in cogeneration. According to that, specific cleaning systems are located at the end of the gasification process in order to make it suitable for the oxidation step in internal combustion engines. Moreover, they avoid any possible damage to the mechanical parts of the gasifier and reduce harmful emissions for environment and human beings. It should be underlined that the most significant problems in the usage of syngas are associated with the presence of particulate, sulfur compounds, and nitrogen $[3,4]$.

\subsection{Gasification Processes}

The "gasification" is the use of heat to transform solid biomass or other carbonaceous solids into a synthetic "natural gas like" flammable fuel. Gasification can convert nearly any dry organic matter into a clean burning, carbon neutral fuel that can replace fossil fuels in many cases. Furthermore, gasification will transform common "waste" into a flexible gaseous fuel which can be successfully used to run internal combustion engine, cooking stove, furnace, or flamethrower. This does not depend on the initial biomass (wood chips, walnut shells, construction debris, or agricultural waste).

Thus, gasification is a partial combustion of solid fuel (biomass): temperatures close to $1000^{\circ} \mathrm{C}$ are required. The reactor is called "gasifier." The combustion products, coming from complete combustion of biomass, generally contain nitrose, water vapor, carbon dioxide, and surplus of oxygen. However, when gasification is characterized by solid fuel surplus (incomplete combustion), the products of combustion are combustible gases, such as carbon monoxide $(\mathrm{CO})$, hydrogen $\left(\mathrm{H}_{2}\right)$, traces of methane and unhelpful products (i.e., tar and char).

The main reactions take place in combustion and reduction zone $[5,6]$. 


\section{Combustion Zone (Exothermic Reactions)}

The combustion products of solid fuel are usually carbon, hydrogen, and oxygen. When complete combustion occurs, carbon dioxide is obtained from hydrogen, usually as steam. The main reactions, therefore, are

$$
\begin{aligned}
& \mathrm{C}+\mathrm{O}_{2} \longrightarrow \mathrm{CO}_{2} \quad \text { (complete combustion) } \\
& \mathrm{C}+\frac{1}{2} \mathrm{O}_{2} \longrightarrow \mathrm{CO} \quad \text { (partial combustion). }
\end{aligned}
$$

\section{Reaction Zone}

The products of partial combustion (water, carbon monoxide, and uncombusted partially cracked pyrolysis) now pass through a red-hot charcoal bed where the following reduction reactions take place:

$$
\begin{gathered}
\mathrm{CO}+\mathrm{H}_{2} \mathrm{O} \longrightarrow \mathrm{CO}_{2}+\mathrm{H}_{2} \quad \text { (water-gas shift reactions) } \\
\mathrm{C}+2 \mathrm{H}_{2} \longrightarrow \mathrm{CH}_{4} \quad \text { (methane formation) } \\
\mathrm{CH}_{4}+\mathrm{H}_{2} \mathrm{O} \longrightarrow \mathrm{CO}+3 \mathrm{H}_{2} \quad \text { (hydrogen formation) } \\
\mathrm{C}+\mathrm{CO}_{2} \longrightarrow 2 \mathrm{CO} \\
\mathrm{C}+\mathrm{H}_{2} \mathrm{O} \longrightarrow \mathrm{CO}+\mathrm{H}_{2} \quad \text { (water-gas reaction) }
\end{gathered}
$$

As residence time of biomass, temperature, and pressure of the process increase, higher fuel conversion occurs. Temperature rises leading to more endothermic reactions and, as a consequence, $\mathrm{CO}$ and $\mathrm{H}_{2}$. High pressure values help those reactions aimed at reducing the number of moles and at producing $\mathrm{CO}_{2}, \mathrm{CH}_{4}$, and $\mathrm{H}_{2} \mathrm{O}$. The content of $\mathrm{CO}$ and $\mathrm{H}_{2}$ is regulated through incoming water as shown in reaction 2.3 called "water gas shift." Humidity content influences the ratio between $\mathrm{CO}$ and $\mathrm{H}_{2}$ and, at the same time, is the most important tool to reduce temperature $[7,8]$.

\subsection{The Downdraft Gasifier Prototype}

The experimental gasifier is a fixed cocurrent bed, fed with hazelnut shells (Figure 1). The developed prototype is a small sized plant. The electrical capacity is $30 \mathrm{~kW}$ and the thermal power reaches $60 \mathrm{~kW}$. The internal structure is made of stainless steel 304 .

The outline of the gasifier (Figure 2) consists of a loading hopper in which hazelnut shells are stored. The hopper (1) is connected to the gasification reactor by means of a cochlea with horizontal axis (2) which allows the biomass to enter the upper part of the reactor (4) and separates the input zone from the combustion air (5). Air enters the reactor from the opening in (3). The biomass conversion into gaseous phase, with the consequent production of ashes, takes place during the descent inside the bed. The obtained syngas comes out from 


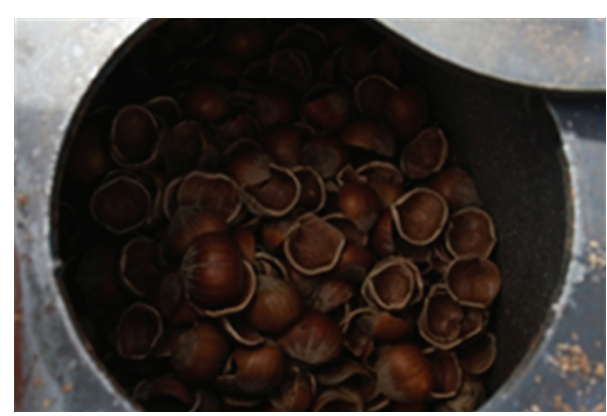

Figure 1: Biomass used in the process.

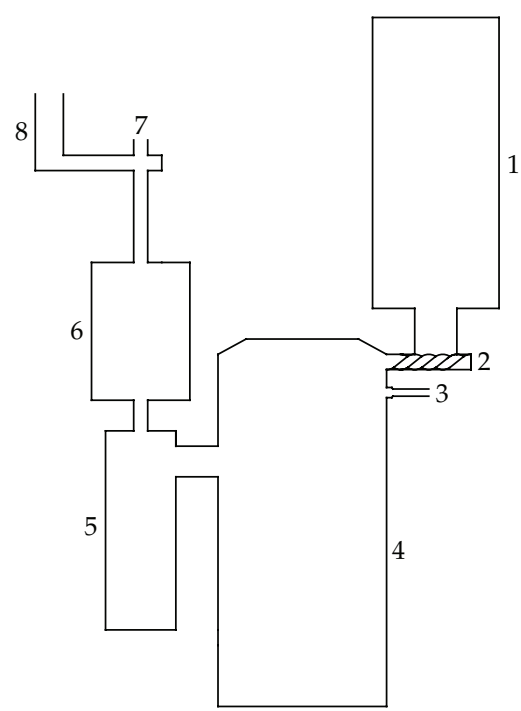

Figure 2: Gasification system layout.

the bottom part of the reactor. Moreover, in order to remove the coarse particulate, it passes first through a cyclone and a cooling air system (3) and then in a filter. The latter step is to clean TAR and smaller sized particles. The gas, leaving the filter, is mixed with air (7) and combusted in torch (8).

Figure 3 shows the detailed layout of the gasification reactor used for the experiments. It is interesting to note that the internal structure is characterized by a narrowing or "throat" where the highest process temperatures occur. They are aimed at TAR thermal cracking which is contained in vapor and comes from pyrolysis in the upper parts. In the part below the throat, reduction reactions occur and lead to the production of the greatest interesting molecular species: $\mathrm{H}_{2}$ and $\mathrm{CO}$.

The gasification test starts with the aid of an initial pilot flame, necessary to allow the achievement of the thermal conditions required for self-maintenance of the gasification process (Figure 4 ).

SKC-1 L Tedlar bags black layered (Figure 5) have been used depending on the biomass quality to analyze the chemical and physical properties of the syngas. The latter has been 


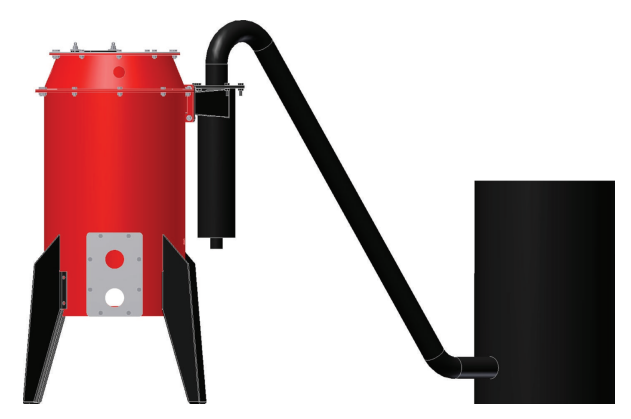

Figure 3: Reactor gasifier layout (Render).

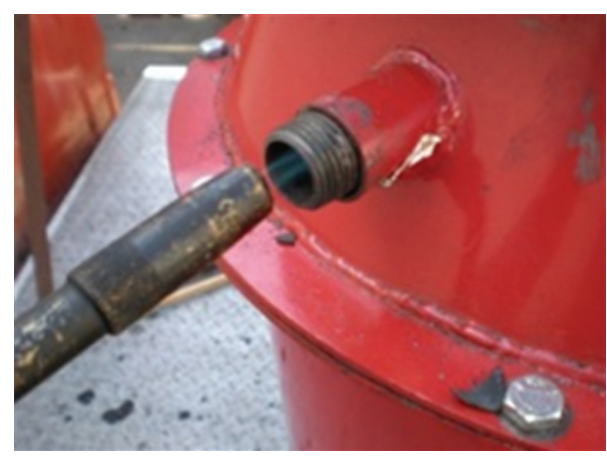

Figure 4: Start phase of the test.

analyzed by gas chromatography in order to point out the main chemical components according to the type of biomass used during the process.

The experiment was carried out under established thermodynamic conditions, necessary for the startup and the maintenance of the gasification process (Figure 6). In more detail, temperature values were detected with the aim of maintaining the process in the suitable range for the optimal biomass conversion into synthesis gas. After adding the biomass into the reactor, the combustion process starts by entering the necessary air and using a pilot flame required for the achievement of process temperatures. Once the thermodynamic conditions-required for the self-maintenance of the thermochemical process-are reached, the test continues without the help of the pilot flame or other external heating sources but only by the introduction of hazelnut shells and combustion air. From this moment on, the sampling gas started. During the gasification test, temperatures between 900 and $1000^{\circ} \mathrm{C}$ are reached inside the reactor with pressure values close to 0.025 bar.

\subsection{Energy Characterization of Biomass: Analysis in Laboratory}

The laboratory tests were carried out at CIRDER (Energy Biomass Certification Laboratory) of the University of Tuscia in Viterbo. Sampling of hazelnut shells, coming from a hazelnut orchard in Caprarola, was carried out according to ISO 14778. 


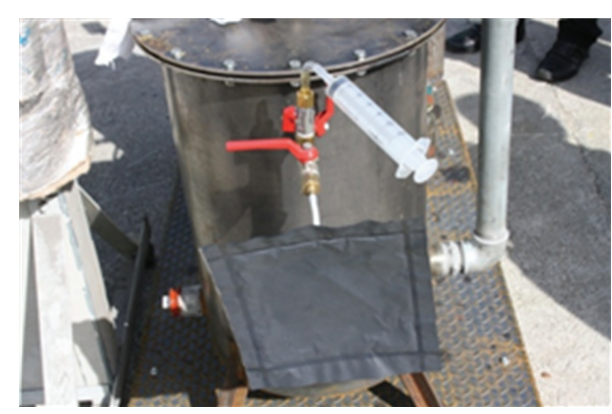

Figure 5: Tedlar bags, before the sampling.

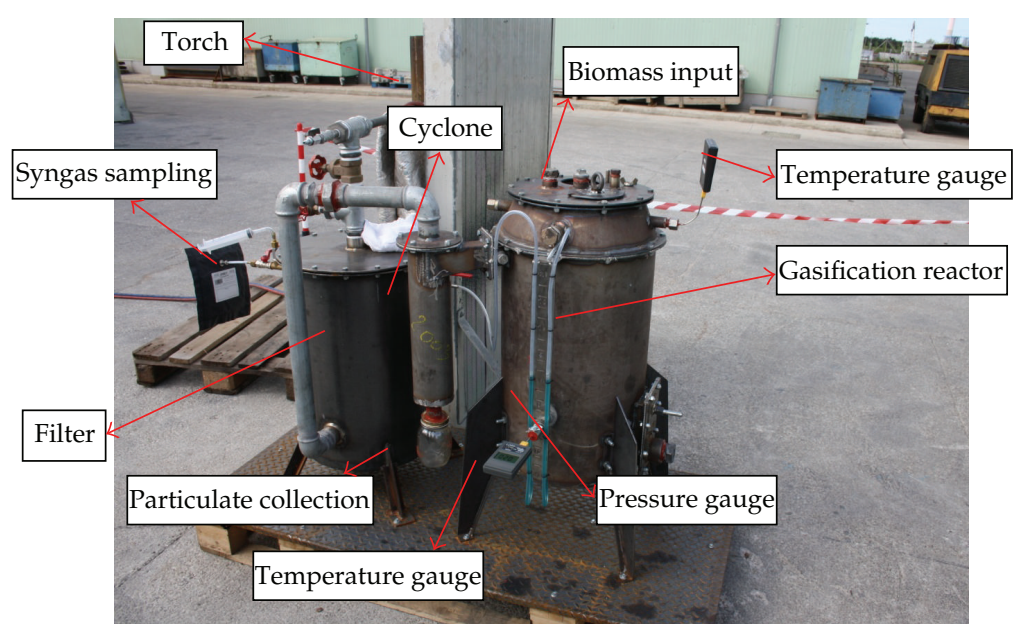

Figure 6: Gasification system.

Table 1: Characterization of hazelnut shells.

\begin{tabular}{lcc}
\hline Parameter & Value & Unit of measurement \\
\hline Moisture content & 6.4 & $\%$ on dry basis \\
Lower calorific value & 18.83 & MJ $/ \mathrm{kg}$ on dry basis \\
Carbon content & 51.14 & $\%$ by mass \\
Hydrogen content & 5.7 & $\%$ by mass \\
Nitrogen content & 0.42 & $\%$ by mass \\
Ash content & 1.71 & $\%$ by mass \\
\hline
\end{tabular}

Table 2: Syngas composition.

\begin{tabular}{lcccccc}
\hline Test number & $\mathrm{H}_{2}[\%]$ & $\mathrm{N}_{2}[\%]$ & $\mathrm{CO}[\%]$ & $\mathrm{CO}_{2}[\%]$ & $\mathrm{CH}_{4}[\%]$ & $\mathrm{O}_{2}[\%]$ \\
\hline 1 & 12.00 & 57.00 & 13.00 & 10.00 & 3.17 & 3.09 \\
2 & 11.83 & 56.12 & 12.50 & 9.97 & 3.11 & 2.86 \\
3 & 11.78 & 56.53 & 13.00 & 10.00 & 3.12 & 2.82 \\
4 & 11.73 & 56.45 & 12.80 & 9.98 & 3.30 & 2.78 \\
5 & 11.81 & 56.43 & 12.98 & 10.2 & 3.24 & 2.74 \\
6 & 11.69 & 56.48 & 12.96 & 10.1 & 3.19 & 2.74 \\
\hline
\end{tabular}




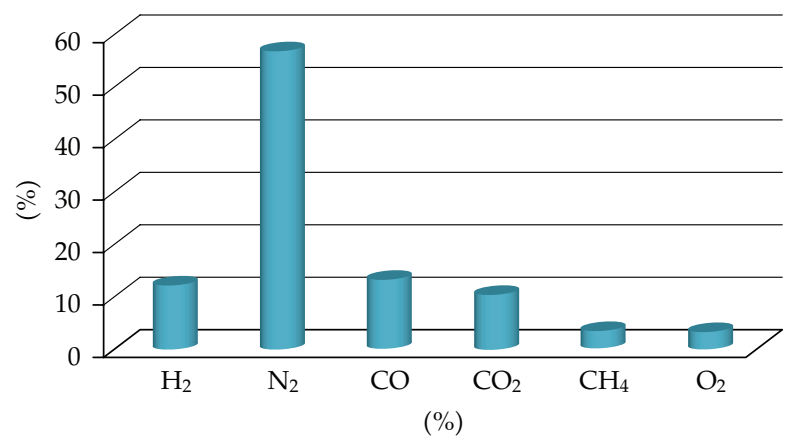

Figure 7: Average composition of the syngas.

The preparation of biomass samples was carried out following ISO 14780 and analysis lead to the determination of moisture content on a dry basis complying with the ISO 14774-1, ash content following ISO 14775, lower calorific value on a dry basis according to ISO 14918 and mass content of carbon, hydrogen, and nitrogen as ISO 15104 established.

The results of analysis-carried out on the hazelnut shells used as biomass in the gasification experiment-are shown in Table 1.

\subsection{Syngas Analysis}

The outgoing gas from the experimental gasifier was analyzed by the gas chromatograph CP-4900 Micro GC Varian in order to estimate the molecular species of gaseous mixture. The syngas is collected in pockets of tedlar through donor sites located along the duct between the filter and the air premixing zone for combustion in torch. Once the bags are filled, the placing of the gas inside the gas chromatography is carried out through the use of a latex tube which acts as a connecting element between the valve of the bag and the analysis tool.

\section{Results and Discussion}

The analysis of the synthesis gas has allowed determination of the molecular species present in the gaseous mixture obtained as the result of hazelnut shells gasification inside the experimental gasifier presented in this paper. The gas chromatography results are shown in Table 2.

Figure 7 shows the average composition of the molecular species present in the gaseous mixture.

$\mathrm{H}_{2}$ and $\mathrm{CO}_{2}$ have been the main components of the syngas produced by the gasification process (Figure 8). Moreover, comparing the results with literature data, it can be seen that the highest values were obtained in the gasification of hazelnut shells, except for $\mathrm{CO}_{2}$. This difference could be due to size, homogeneity, and a better calorific value, which is the main factor for thermochemical processes like gasification.

Literature fixes the syngas quality on the basis of the oxidant agents; keeping the same oxidant agents, highest values of the syngas components have been founded than the ones previously stated (Figure 8 and Table 3). 


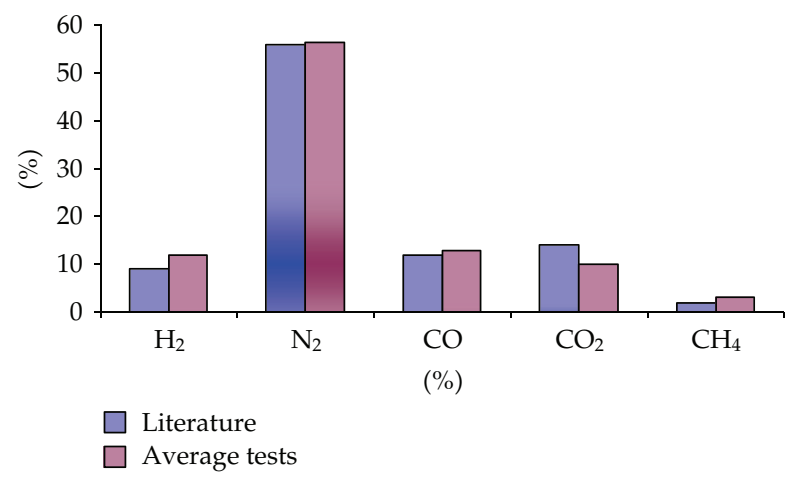

Figure 8: Comparison between literature data and tests average.

Table 3: Syngas quality on the basis of oxidant agents (ISES Italia, 2005) [4].

\begin{tabular}{lccc}
\hline$\%$ & Air & Oxygen & Water vapour \\
\hline $\mathrm{CO}$ & $12-15$ & $30-37$ & $32-41$ \\
$\mathrm{CO}_{2}$ & $14-17$ & $25-29$ & $17-19$ \\
$\mathrm{H}_{2}$ & $9-10$ & $30-34$ & $24-26$ \\
$\mathrm{CH}_{4}$ & $2-4$ & $4-6$ & 12.4 \\
$\mathrm{~N}_{2}$ & $56-59$ & $2-5$ & 2.5 \\
\hline
\end{tabular}

In particular tests showed a proportional increase of $\mathrm{H}_{2}(2.8 \%), \mathrm{CO}(0.87 \%)$, and $\mathrm{CH}_{4}$ (around $1.1 \%$ ) and a proportional decrease of $\mathrm{CO}_{2}$ and $\mathrm{N}_{2}$. Generally, the results show that the produced syngas is relatively rich in carbon dioxide, methane, and hydrogen and also contains a large amount of nitrogen.

The carbon dioxide resulting from partial combustion process takes place simultaneously with biomass gasification. The prototype worked properly producing good quality syngas. However, it should be noted that it could be improved, providing a better automation and electronic system. This is to ensure technical and economical sustainability. Further researches will be carried out in the future.

\section{Authors' Contribution}

The authors' contribution to this paper can be considered equal.

\section{Acknowledgment}

The authors would like to thank Mrs. Elena Allegrini, Ph.D. student at the Department of Agriculture, Forest, Nature and Energy (DAFNE), University of Tuscia, for her support and help in drafting the present paper. 


\section{References}

[1] D. Monarca, M. Carlini, M. Cecchini, and A. Colantoni, "Gasification of agroforestry biomasses by means of a multi-reactor gasifier for electric power production: experimental tests and syngas analysis," Annual Review of Agricultural Engineering, vol. 7, no. 1, pp. 57-64, 2009.

[2] D. Monarca, M. Cecchini, A. Colantoni, and A. Marucci, "Feasibility of the electric energy production through gasification processes of biomass: technical and economic aspects," in Proceedings of the Computational Science and its Applications (ICCSA '11), vol. 4 of Lecture Notes in Computer Science, pp. 307-315, Springer, Santander, Spain, June 2011.

[3] G. Bruni, R. Solimene, A. Marzocchella et al., "Self-segregation of high-volatile fuel particles during devolatilization in a fluidized bed reactor," Powder Technology, vol. 128, no. 1, pp. 11-21, 2002.

[4] A. Çağlar and A. Demirbaş, "Hydrogen rich gas mixture from olive husk via pyrolysis," Energy Conversion and Management, vol. 43, no. 1, pp. 109-117, 2002.

[5] S. T. Chaudhari, S. K. Bej, N. N. Bakhshi, and A. K. Dalai, "Steam gasification of biomass-derived char for the production of carbon monoxide-rich synthesis gas," Energy and Fuels, vol. 15, no. 3, pp. 736-742, 2001.

[6] P. Morf, P. Hasler, and T. Nussbaumer, "Mechanisms and kinetics of homogeneous secondary reactions of tar from continuous pyrolysis of wood chips," Fuel, vol. 81, no. 7, pp. 843-853, 2002.

[7] P. McKendry, "Energy production from biomass-part 3-: gasification technologies," Bioresource Technology, vol. 83, no. 1, pp. 55-63, 2002.

[8] T. A. Milne and R. J. Evans, "Biomass gasifier "Tars": their nature, formation, and conversion," Tech. Rep. NREL/TP-570-25357, NREL, Golden, Colo, USA, 1998. 


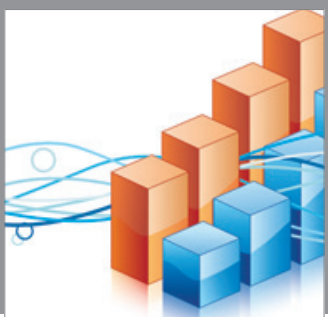

Advances in

Operations Research

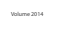

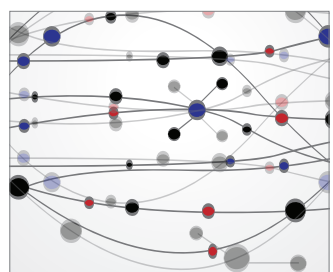

\section{The Scientific} World Journal
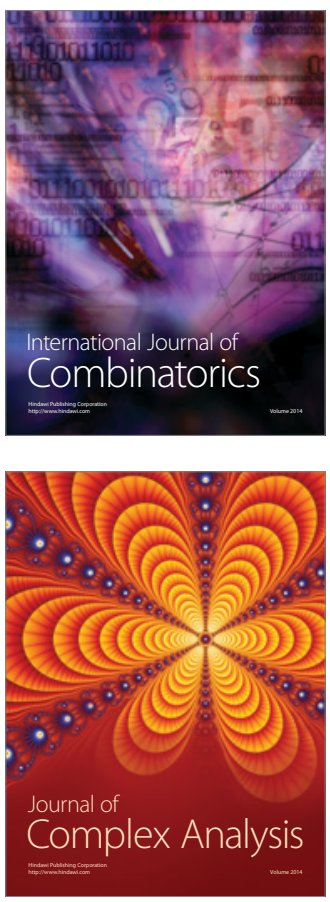

International Journal of

Mathematics and

Mathematical

Sciences
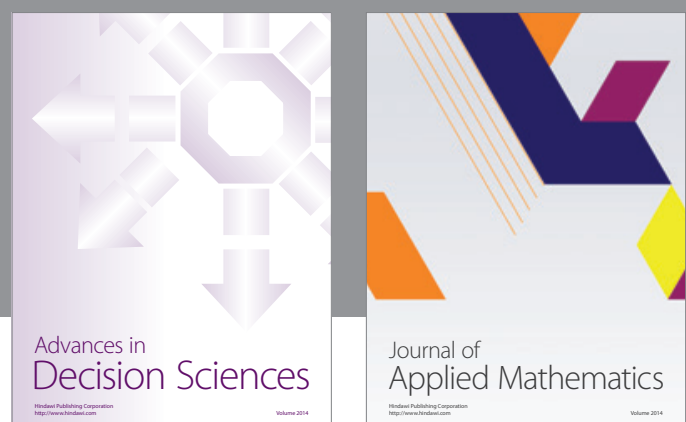

Journal of

Applied Mathematics
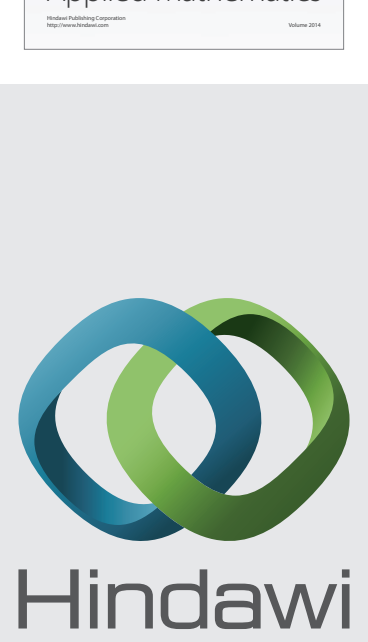

Submit your manuscripts at http://www.hindawi.com
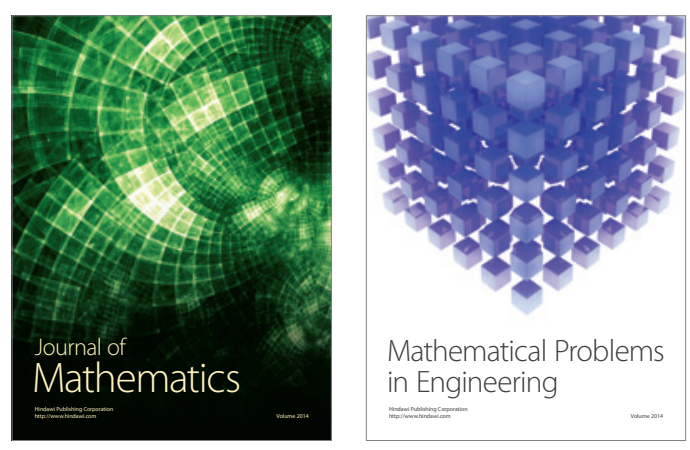

Mathematical Problems in Engineering
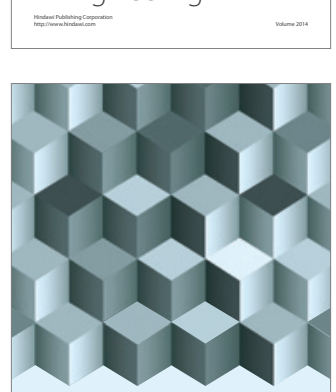

Journal of

Function Spaces
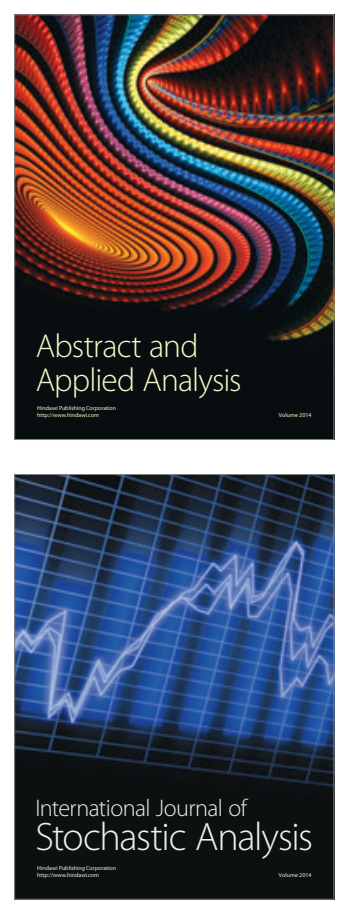

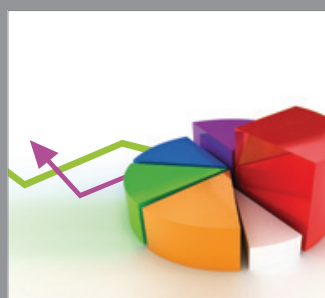

ournal of

Probability and Statistics

Promensencen
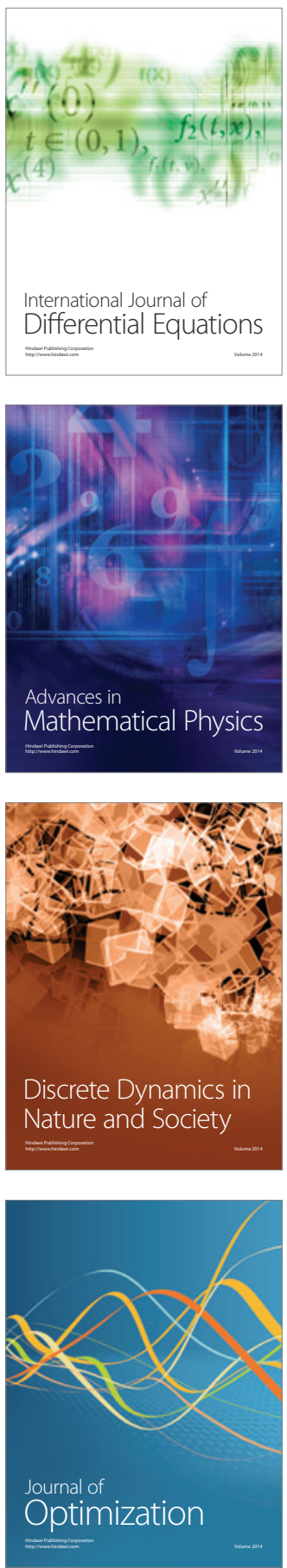